\title{
Bicyclist Stress Perceptions and Heart Rate Variability
}

Dillon Fitch ${ }^{1}$ (1)

${ }^{1}$ Institute of Transportation Studies, University of California, Davis

Keywords: bicyclist stress, heart rate variability, bicycling safety, bicycling comfort, physiological stress markers

https://doi.org/10.32866/001c.28138

Findings

This paper describes the relationship between a physiological marker of stress (heart rate variability) and survey-based stress responses from a cross-over realworld bicycling experiment. The analysis shows that while heart rate variability was inversely associated with survey-based estimates of stress, large uncertainty in the relationship indicates carefully controlled experiments are still needed before we can be confident that bicyclist stress can be measured through heart rate variability.

\section{QUESTIONS}

In this article I examine the relationship between people's stated perceptions of bicycling stress and their heart rate variability (HRV). Objective psychological measures of stress have the potential to aid identification of road environment factors that affect bicyclist comfort and safety, both key barriers to bicycling (Buehler and Dill 2016; Heinen, van Wee, and Maat 2010). I hypothesized that heart rate variability (low heart rate variability is a marker for a stressed psychological state) would be inversely associated with survey-based measures of stress from bicycling experiences. I focus on evaluating this hypothesis and exploring the following research questions:

1. Does heart rate variability have a consistent relationship with survey responses indicative of "stressful" bicycling?

2. Do heart rate variability and survey response relationships vary by road environments and type of stressor?

\section{METHODS}

Using data from a prior cross-over bicycling field experiment (see Fitch et al. (2020) for details), I examine data from 20 female college undergraduates who bicycled on five road conditions, answering eight survey items about stress with ordered categorical responses for each road condition (Table 1). Each participant rode at a comfortable pace with their usual bicycle on five flat road conditions, with rests in-between, during times of low heat and low wind (to avoid physical exertion). Because the survey data was collected after each participant's ride on each road condition, HRV is aggregated over the duration of each road condition (i.e., not as a metric for detecting "moments of stress"). The limitation of this approach is that a participant's HRV is reflecting stimuli of all kinds, not just threat-type stressors, adding to measurement noise. 
Table 1. Variable Descriptions

\begin{tabular}{|c|c|c|}
\hline $\begin{array}{l}\text { Variable } \\
\text { Type }\end{array}$ & \multicolumn{2}{|l|}{ Variable Description } \\
\hline \multirow{2}{*}{$\begin{array}{l}\text { Rating } \\
\text { (Ordered } \\
\text { Categories) } \\
\end{array}$} & \multicolumn{2}{|l|}{ Prompt: In the bike ride you just finished, did you feel... } \\
\hline & \multicolumn{2}{|c|}{ Response Categories: Not at all (1), A little (2), Sometimes (3), Often (4), A lot (5) } \\
\hline \multirow{8}{*}{$\begin{array}{l}\text { Survey Item } \\
\text { (index) }\end{array}$} & 1 & ...emotionally tired? \\
\hline & 2 & ...physically tired? \\
\hline & 3 & ...comfortable? [reversed to uncomfortable] \\
\hline & 4 & $\begin{array}{l}\text {...protected from traffic? [reversed to unprotected from } \\
\text { traffic] }\end{array}$ \\
\hline & 5 & ...safe? [reversed to unsafe] \\
\hline & 6 & ...worried about turning vehicles? \\
\hline & 7 & ...worried about parked car doors? \\
\hline & 8 & ...worried about passing vehicles? \\
\hline \multicolumn{2}{|l|}{ Person (index) } & $\{1, \ldots, 20\}$ \\
\hline \multirow{5}{*}{$\begin{array}{l}\text { Road } \\
\text { Condition } \\
\text { (indicators) }\end{array}$} & College Park (base case) & $\begin{array}{l}\text { Low speed (no data) local road, 2-lane, no road } \\
\text { centerline, on-street parking, low traffic (average daily } \\
\text { cars unknown) }\end{array}$ \\
\hline & Oak Ave. & $\begin{array}{l}\text { Low speed (no data) collector, 2-lane, road centerline, } \\
\text { bike lane, on-street parking, low traffic (average daily } \\
\text { cars 2,000) }\end{array}$ \\
\hline & B St. & $\begin{array}{l}\text { Low speed ( } 25 \mathrm{mph} \text { ) collector, } 2 \text {-lane, road centerline, } \\
\text { buffered bike lane, no on-street parking, moderate } \\
\text { traffic (average daily cars } \sim 6,000 \text { ) }\end{array}$ \\
\hline & Anderson Rd. & $\begin{array}{l}\text { Medium speed ( } 25-30 \mathrm{mph} \text { ) collector, } 2 \text {-lane, road } \\
\text { centerline, bike lane, on-street parking, moderate } \\
\text { traffic (average daily cars } \sim 10,000)\end{array}$ \\
\hline & Russell Blvd. & $\begin{array}{l}\text { Medium speed ( } 30-35 \mathrm{mph} \text { ) arterial, 4-lane, center } \\
\text { median, no bike lane, on-street parking mixed, high } \\
\text { traffic (average daily cars } \sim 20,000 \text { ) }\end{array}$ \\
\hline \multicolumn{2}{|l|}{ HF-HRV (ms) } & $\begin{array}{l}\text { Standard deviation of high frequency filtered inter- } \\
\text { heart-beat intervals }\end{array}$ \\
\hline \multicolumn{3}{|c|}{ Average Speed (mps) } \\
\hline $\begin{array}{l}\text { Bicycling } \\
\text { Ability }\end{array}$ & $\begin{array}{l}\text { How would you classify your bicycling ability? By } \\
\text { ability we mean your balance, steering, and general } \\
\text { technical control of your bicycle. }\end{array}$ & $\begin{array}{l}\text { Z-score of numeric index: beginner (1) } \\
\text { advanced beginner ( } 2 \text { ) } \\
\text { intermediate ( } 3 \text { ) } \\
\text { advanced ( } 4 \text { ) } \\
\text { expert (5) }\end{array}$ \\
\hline $\begin{array}{l}\text { Bicycling } \\
\text { Desire (one } \\
\text { item) }\end{array}$ & I bike as often as I can & \multirow{2}{*}{$\begin{array}{l}\text { Z-score of numeric index: } \\
\text { strongly disagree (1) } \\
\text { somewhat disagree (2) } \\
\text { neither disagree nor agree (3) } \\
\text { somewhat agree (4) } \\
\text { strongly agree (5) }\end{array}$} \\
\hline $\begin{array}{l}\text { Bicycling } \\
\text { Vigilance } \\
\text { (two-item } \\
\text { average) }\end{array}$ & $\begin{array}{l}\text { I am a cautious bicyclist } \\
\text { When bicycling, I always keep a watchful eye on cars }\end{array}$ & \\
\hline
\end{tabular}

The data at the road condition level has a total sample size of 792 ratings (one participant failed to ride on the correct route for one condition which resulted in missing data for 8 ratings). The primary predictor of interest is the standard deviation of high frequency filtered inter-heart-beat intervals, also called high frequency heart rate variability (HF-HRV). I extracted the HF-HRV from inter-heart-beat intervals using the maximal overlap discrete wavelet transform (MODWT) where frequency filter parameters vary based on person-specific inter-heart-beat time series making the metric a person-scaled standardized 
measure of HF-HRV (see Fitch et al. (2020) for details about signal processing). HF-HRV is a commonly used marker for psychological stress due to its close connection to vagal tone (the physiological basis of all current theories linking HRV to psychology) (Laborde, Mosley, and Thayer 2017). The important moderators of interest are the road condition levels and the survey items. I selected four additional co-variates in this analysis based on the prior study, they include average speed to adjust for physical exertion's influence on the heart, and survey measures of bicycling vigilance, ability, and desire which adjust for some person-level differences in stress response to on-road bicycling.

To examine how HF-HRV influenced post-ride stress ratings, I estimated a Bayesian multilevel (by person and survey item) ordered logistic regression model using the R package brms (Bürkner 2017), an interface for the Stan computing language (Stan Development Team 2018) (See supplemental material for model details). I ensured that the model converged, that no Stan diagnostic warnings occurred, and that the model was regularized to guard against overfitting by using "weakly informative" priors on all parameters (McElreath 2020), selected from prior predictive visual plots.

\section{FINDINGS}

The model results are compatible with my original hypothesis, people who had high HF-HRV while bicycling were less likely to agree with statements of stressful experiences on average $\left(B_{H}\right.$, Table 2 , and negative slopes in Figure 1 ), but the uncertainty in the mean effect makes the evidence unconvincing. Person-level variation in this relationship is small $\left(\sigma_{\beta_{H, p}}\right.$, Table 2 , slopes of thin lines in Figure 1), especially compared to person-level variation in ratings on average $\left(\sigma_{p}\right.$, Table 2).

The variation in the relationship between HF-HRV and survey-based stress ratings by road condition and survey items are also small (Figure 1), and most of that variation is imprecisely estimated by the model $\left(\beta_{H C 1}, \beta_{H C 2}, \beta_{H C 3}, \beta_{H C 4}, \sigma_{\beta_{H I}}\right.$, Table 2). Like the person-level variation, the moderating effects of road condition and item on ratings $\left(\beta_{C 1}, \beta_{C 2}, \beta_{C 3}, \beta_{C 4}, \sigma_{I}\right.$, Table 2$)$ are much greater than the moderation of those effects on the relationship between HF-HRV and ratings. The lack of item-level moderation on the relationship between HF-HRV and ratings suggests HF-HRV did not help distinguish types of stressors nor types of stress perceptions.

The moderating effects of the interaction between road condition and survey item on the relationship between HF-HRV and ratings are again, small $\left(\sigma_{\beta_{H C 1, I}}, \sigma_{\beta_{H C 2, I}}, \sigma_{\beta_{H C 3, I}}, \sigma_{\beta_{H C 4, I}}\right.$, Table 2). Overall, the general trend of low HFHRV predicting greater agreement with the stress statements is mostly consistent across road conditions and survey items (negative slopes in all panels of Figure 1), albeit with great uncertainty. 
Table 2. Selected Model Parameter Summaries

\begin{tabular}{|c|c|c|c|}
\hline Parameter Description & Parameter* & Mean & sd \\
\hline Threshold [1] & $\alpha_{1}$ & 1.618 & 0.665 \\
\hline Threshold [2] & $\alpha_{2}$ & 4.351 & 0.677 \\
\hline Threshold [3] & $a_{3}$ & 6.200 & 0.702 \\
\hline Threshold [4] & $a_{4}$ & 8.565 & 0.775 \\
\hline Road Condition (B) & $\beta_{C 1}$ & 2.362 & 0.705 \\
\hline Road Condition (Oak) & $\beta_{C 2}$ & 1.529 & 0.689 \\
\hline Road Condition (Anderson) & $\beta_{C 3}$ & 2.791 & 0.663 \\
\hline Road Condition (Russell) & $\beta_{C 4}$ & 4.961 & 1.093 \\
\hline HF-HRV & $B_{H}$ & -0.423 & 0.691 \\
\hline Bicycling Vigilance & $\beta_{V}$ & 0.284 & 0.357 \\
\hline Bicycling Ability & $\beta_{A}$ & -0.751 & 0.304 \\
\hline Bicycling Desire & $\beta_{D}$ & -0.449 & 0.330 \\
\hline HF-HRV $\times$ Average Speed & $\beta_{\mathrm{HS}}$ & 0.111 & 0.162 \\
\hline Road Condition $(\mathrm{B}) \times \mathrm{HF}-\mathrm{HRV}$ & $\beta_{H C 1}$ & 0.015 & 0.212 \\
\hline Road Condition (Oak) $\times$ HF-HRV & $\beta_{H C 2}$ & 0.093 & 0.218 \\
\hline Road Condition (Anderson) $\times$ HF-HRV & $\beta_{H C 3}$ & -0.074 & 0.309 \\
\hline Road Condition (Russell) $\times$ HF-HRV & $\beta_{H C 4}$ & 0.150 & 0.355 \\
\hline sd(Intercept) [Survey Item] & $\sigma_{1}$ & 0.698 & 0.352 \\
\hline sd(Road Condition (B)) [Survey Item] & $\sigma_{\beta_{C 1, I}}$ & 0.742 & 0.420 \\
\hline sd(Road Condition (Oak)) [Survey Item] & $\sigma_{\beta_{C 2,1}}$ & 0.424 & 0.330 \\
\hline sd(Road Condition (Anderson)) [Survey Item] & $\sigma_{\beta_{C 3,1}}$ & 0.478 & 0.368 \\
\hline sd(Road Condition (Russell)) [Survey Item] & $\sigma_{\beta C 4,}$ & 1.779 & 0.615 \\
\hline sd(HF-HRV) [Survey Item] & $\sigma_{\beta_{H, I}}$ & 0.067 & 0.064 \\
\hline sd(HF-HRV $\times$ Average Speed) [Survey Item] & $\sigma_{\beta_{H S, 1}}$ & 0.016 & 0.015 \\
\hline sd(Road Condition (B) $\times$ HF-HRV) [Survey Item] & $\sigma_{\beta_{H C 1, I}}$ & 0.104 & 0.086 \\
\hline sd(Road Condition (Oak) $\times$ HF-HRV) [Survey Item] & $\sigma_{\beta_{H C 2,1}}$ & 0.129 & 0.095 \\
\hline sd(Road Condition (Anderson) $\times$ HF-HRV) [Survey Item] & $\sigma_{\beta_{H C 3, I}}$ & 0.127 & 0.104 \\
\hline sd(Road Condition (Russell) × HF-HRV) [Survey Item] & $\sigma_{\beta_{H C 4,1}}$ & 0.202 & 0.155 \\
\hline sd(Intercept) [Person Index] & $\sigma_{p}$ & 1.029 & 0.372 \\
\hline sd(Road Condition (B)) [Person Index] & $\sigma_{\beta}$ & 1.033 & 0.429 \\
\hline sd(Road Condition (Oak)) [Person Index] & $\sigma_{\beta C 2, p}$ & 0.876 & 0.504 \\
\hline sd(Road Condition (Anderson)) [Person Index] & $\sigma_{\beta}{ }_{C 3, p}$ & 0.653 & 0.433 \\
\hline sd(Road Condition (Russell)) [Person Index] & $\sigma_{\beta} c_{4, p}$ & 1.630 & 0.513 \\
\hline $\mathrm{sd}(\mathrm{HF}-\mathrm{HRV})[$ Person Index] & $\sigma_{\beta_{H, p}}$ & 0.157 & 0.120 \\
\hline sd(HF-HRV $\times$ Average Speed) [Person Index] & $\sigma_{\beta_{H S D}}$ & 0.033 & 0.027 \\
\hline sd(Road Condition (B) $\times$ HF-HRV) [Person Index] & $\sigma_{\beta_{H C 1, p}}$ & 0.168 & 0.155 \\
\hline sd(Road Condition (Oak) × HF-HRV) [Person Index] & $\sigma_{\beta}{ }_{H C 2, p}$ & 0.256 & 0.181 \\
\hline sd(Road Condition (Anderson) $\times$ HF-HRV) [Person Index] & $\sigma_{\beta_{H C 3, p}}$ & 0.468 & 0.207 \\
\hline $\mathrm{sd}($ Road Condition (Russell) $\times$ HF-HRV) [Person Index] & $\sigma_{\beta_{H C 4 N}}$ & 0.321 & 0.235 \\
\hline
\end{tabular}

${ }^{*}$ Correlation parameters and varying effects are not reported.

The scant but growing evidence (Doorley et al. 2015; Jones et al. 2016; Caviedes and Figliozzi 2018; Teixeira et al. 2020; Fitch, Sharpnack, and Handy 2020; Werner, Resch, and Loidl 2019; Zeile et al. 2016) that bicyclist stress can be estimated through physiological markers should be scrutinized and reconsidered. What are physiological markers really measuring in bicycling studies? Are these recent studies chasing noise or demonstrating important 


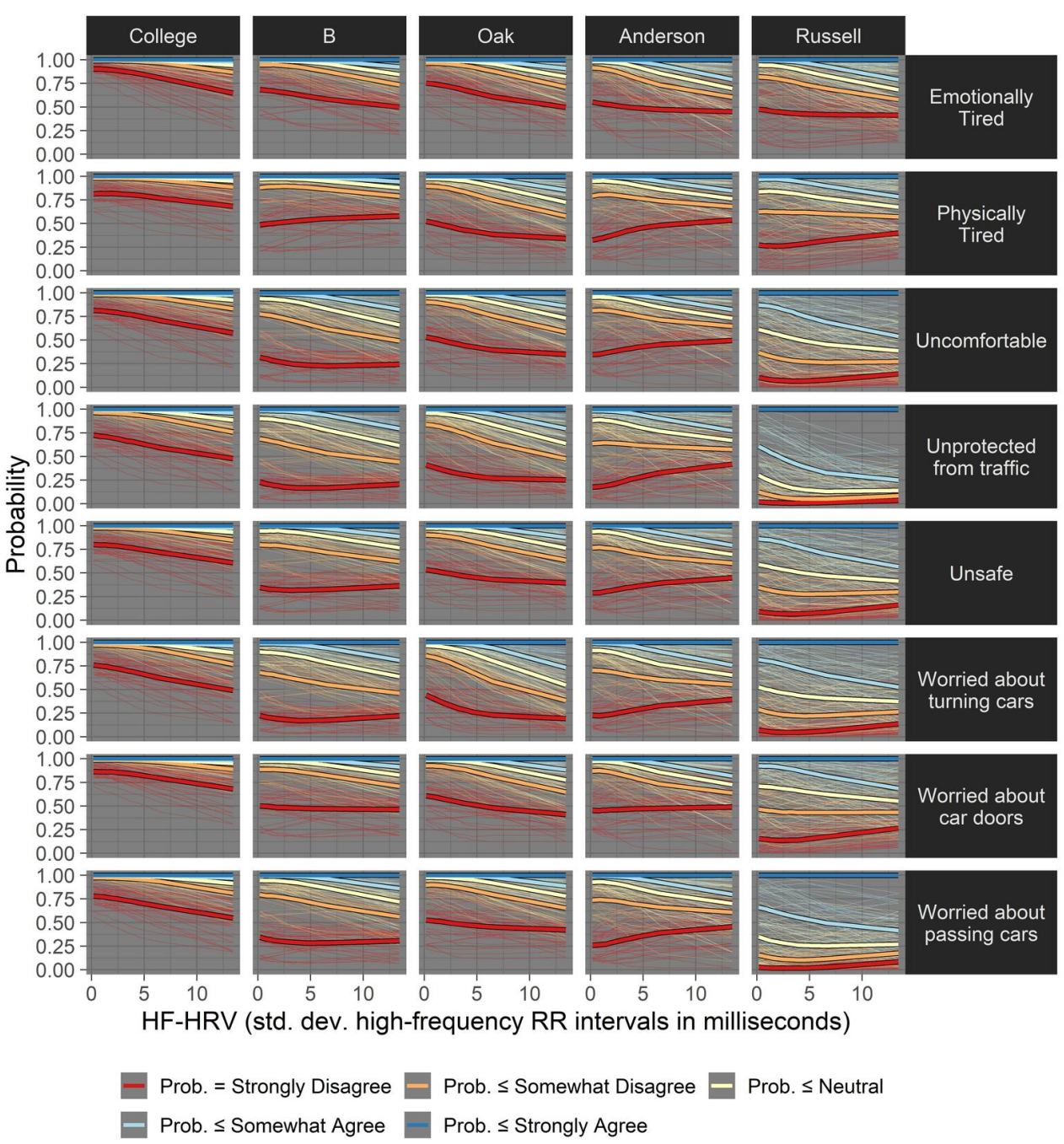

Figure 1. Mean (thick lines) and person-level (thin lines) predicted probability of survey response by HF-HRV for combinations of road condition and survey item while holding other variables at their means.

human-environment interactions? While physiological markers attempt to measure pre-cognitive (or sub-conscious) stress responses, they probably should be strongly associated with conscious evaluations of stress to be deemed valid stress markers. Given existing bicyclist stress studies, including this one, evidence is weak on this connection. While this study attempted to control (both experimentally (see Fitch et al. (2020)) and statistically) important confounds, the number of potential confounds to consider in such experiments are much more numerous (Laborde, Mosley, and Thayer 2017; Ausri and Bigazzi 2021). The differences in HF-HRV found between road conditions in Fitch et al. (2020) may have less to do with psychological stress, and more to do with other factors. These findings suggest that HRV and other physiological markers of bicyclist stress need more measurement validation by including survey-based measures of stress in tandem with physiological variables in experiments that have stronger controls for potential confounds. 


\section{ACKNOWLEDGEMENTS}

I would like to thank all the research participants for their participation. This research was funded in part by the National Center for Sustainable Transportation (NCST) at UC Davis.

Submitted: July 30, 2021 AEDT, Accepted: September 10, 2021 AEDT

This is an open-access article distributed under the terms of the Creative Commons Attribution 4.0 International License (CCBY-SA-4.0). View this license's legal deed at https://creativecommons.org/ licenses/by-sa/4.0 and legal code at https://creativecommons.org/licenses/by-sa/4.0/legalcode for more information. 


\section{REFERENCES}

Ausri, F., and A. Bigazzi. 2021. "Physiological Markers of Traffic-Related Stress during Active Travel." In 100th Annual Meeting of Transportation Research Board. Remote.

Buehler, Ralph, and Jennifer Dill. 2016. "Bikeway Networks: A Review of Effects on Cycling.” Transport Reviews 36 (1): 9-27. https://doi.org/10.1080/01441647.2015.1069908.

Bürkner, Paul Christian. 2017. “Brms: An R Package for Bayesian Multilevel Models Using Stan.” Journal of Statistical Software 80 (1). https://doi.org/10.18637/jss.v080.i01.

Caviedes, Alvaro, and Miguel Figliozzi. 2018. "Modeling the Impact of Traffic Conditions and Bicycle Facilities on Cyclists' on-Road Stress Levels." Transportation Research Part F: Traffic Psychology and Behaviour 58: 488-99. https://doi.org/10.1016/j.trf.2018.06.032.

Doorley, Ronan, Vikram Pakrashi, Eoin Byrne, Samuel Comerford, Bidisha Ghosh, and John A Groeger. 2015. "Analysis of Heart Rate Variability amongst Cyclists under Perceived Variations of Risk Exposure." Transportation Research Part F: Psychology and Behaviour 28: 40-54. https://doi.org/10.1016/j.trf.2014.11.004.

Fitch, Dillon T, James Sharpnack, and Susan L Handy. 2020. "Psychological Stress of Bicycling with Traffic: Examining Heart Rate Variability of Bicyclists in Natural Urban Environments.” Transportation Research Part F: Psychology and Behaviour 70: 81-97. https://doi.org/10.1016/ j.trf.2020.02.015.

Heinen, Eva, Bert van Wee, and Kees Maat. 2010. "Commuting by Bicycle: An Overview of the Literature.” Transport Reviews 30 (1): 59-96. https://doi.org/10.1080/01441640903187001.

Jones, T., K. Chatterjee, J. Spinney, E. Street, C. Van Reekum, B. Spencer, H. Jones, et al. 2016. Cycle BOOM. Design for Lifelong Health and Wellbeing. Summary of Key Findings and Recommendations. Oxford Brookes University, UK.: Oxford Brookes University, UK.

Laborde, Sylvain, Emma Mosley, and Julian F. Thayer. 2017. "Heart Rate Variability and Cardiac Vagal Tone in Psychophysiological Research - Recommendations for Experiment Planning, Data Analysis, and Data Reporting." Frontiers in Psychology 8 (FEB): 1-18. https://doi.org/10.3389/ fpsyg.2017.00213.

McElreath, Richard. 2020. Statistical Rethinking 2: A Bayesian Course with Examples in R and Stan. Second. Chapman \& Hall/CRC. https://doi.org/10.1080/09332480.2017.1302722.

Stan Development Team. 2018. "Stan Modeling Language. User's Guide and Reference Manual, 1-488.” 2018. http://mc-stan.org/manual.html\%5Cnpapers2://publication/uuid/ C0937B19-1CC1-423C-B569-3FDB66090102.

Teixeira, Inaian Pignatti, Antônio Nélson, Tim Schwanen, Gustavo Garcia, Linda Dörrzapf, Peter Zeile, Luc Dekoninck, and Dick Botteldooren. 2020. "Does Cycling Infrastructure Reduce Stress Biomarkers in Commuting Cyclists? A Comparison of Five European Cities." Journal of Transport Geography 88 (August): 102830. https://doi.org/10.1016/j.jtrangeo.2020.102830.

Werner, Christian, Bernd Resch, and M Loidl. 2019. "Evaluating Urban Bicycle Infrastructures through Intersubjectivity of Stress Sensations Derived from Physiological Measurements." ISPRS International Journal of Geo-Information.

Zeile, Peter, Bernd Resch, Martin Loidl, and Andreas Petutschnig. 2016. "Urban Emotions and Cycling Experience - Enriching Traffic Planning for Cyclists with Human Sensor Data." GI Forum 1 (2013): 204-16. https://doi.org/10.1553/giscience2016. 


\section{SUPPLEMENTARY MATERIALS}

\section{Supplemental Information}

Download: https://findingspress.org/article/28138-bicyclist-stress-perceptions-and-heart-ratevariability/attachment/70661.docx

\section{r-code}

Download: https://findingspress.org/article/28138-bicyclist-stress-perceptions-and-heart-ratevariability/attachment/70662.txt 